\title{
IMMUNE CHECKPOINT INHIBITORS FOR METASTATIC BLADDER CANCER
}

Francesco Massari, ${ }^{\mathrm{a}, \#, *}$, Vincenzo Di Nunno ${ }^{\mathrm{a},{ }^{*}}$, Marta Cubelli ${ }^{\mathrm{a}}$, Matteo Santoni ${ }^{\mathrm{b}}$, Michelangelo Fiorentino $^{\mathrm{c}}$, Rodolfo Montironi ${ }^{\mathrm{d}}$, Liang Cheng ${ }^{\mathrm{e}}$, Antonio Lopez-Beltran ${ }^{\mathrm{f}}$, Nicola Battelli, Andrea Ardizzoni ${ }^{\mathrm{a}}$.

*Equally contributors

${ }^{a}$ Division of Oncology, S.Orsola-Malpighi Hospital, Bologna, Italy

${ }^{\mathrm{b}}$ Oncology Unit, Macerata Hospital, Macerata, Italy

${ }^{c}$ Pathology Service, Addarii Institute of Oncology, S-Orsola-Malpighi Hospital, Bologna, Italy

${ }^{\mathrm{d}}$ Section of Pathological Anatomy, Polytechnic University of the Marche Region, School of Medicine, United Hospitals, Ancona, Italy

${ }^{\mathrm{e}}$ Department of Pathology and Laboratory Medicine, Indiana University School of Medicine, Indianapolis, IN,

USA;

${ }^{\mathrm{f}}$ Unit of Anatomical Pathology, Faculty of Medicine, Cordoba University, Cordoba, Spain

\#Corresponding author: Francesco Massari MD, Division of Oncology, S.Orsola-Malpighi Hospital, Bologna, Italy. E-mail: fmassari79@gmail.com, phone: +390512142223

This is the author's manuscript of the article published in final edited form as:

Massari, F., Di Nunno, V., Cubelli, M., Santoni, M., Fiorentino, M., Montironi, R., ... Ardizzoni, A. (2018). Immune checkpoint inhibitors for metastatic bladder cancer. Cancer Treatment Reviews. 


\section{ABSTRACT}

Chemotherapy has represented the standard therapy for unresectable or metastatic urothelial carcinoma for more than 20 years. The growing knowledge of the interaction between tumour and immune system has led to the advent of new classes of drugs, the immune-checkpoints inhibitors, which are intended to change the current scenario.

To date, immunotherapy is able to improve the overall responses and survival. Moreover, thanks to its safety profile immune-checkpoint inhibitors could be proposed also to patients unfit for standard chemotherapy.

No doubts that these agents have started a revolution expected for years, but despite this encouraging results it appears clear that not all subjects respond to these agents and requiring the development of reliable predictive response factors able to isolate patients who can more benefit from these treatments as well as new strategies aimed to improve immunotherapy clinical outcome. In this review we describe the active or ongoing clinical trials involving Programmed Death Ligand 1 (PD-L1), Programmed Death receptor 1 (PD-1) and Cytotoxic-T Lymphocyte Antigen 4 (CTLA 4) inhibitors in urothelial carcinoma focusing our attention on the developing new immune-agents and combination strategies with immune-checkpoint inhibitors.

Keywords: Urothelial carcinoma, immune-checkpoint inhibitors, Pembrolizumab, Atezolizumab, Avelumab, Durvalumab, Nivolumab, Ipilimumab, combination therapy. 


\section{INTRODUCTION}

Urothelial cancer of the bladder, renal pelvis, ureter and other urinary organs is the most common malignancy involving the urinary system and the ninth most common malignancy worldwide, with about 430000 new cases diagnosed in 2012 [1].

In metastatic or unresectable disease, Cisplatin combination regimens have represented the standard First line therapy for patients with good performance status while patients unfit to Cisplatin were generally treated with Carboplatin regimens or platinum-free combinations containing taxanes and gemcitabine with an Overall Survival (OS) benefit achieved of 14 months [2-5].

After progression to first line several drugs have been tested without significant improvement in mOS except for Vinfluine, which showed an OS benefit only in eligible patients population compared to best supportive care in a phase III trial $[6,7]$.

From more than 20 years no active treatments have shown to improve clinical outcome of patients with UC compared to chemotherapy. This until the demonstration that bladder cancer, like melanoma and non small cell lung cancer, is a tumour with a high somatic mutation frequencies and a high antigenic expression resulting in an optimal target for immune-checkpoint inhibitors [8].

PD-1 and PD-L1 are members of the Ig superfamily expressed on hematopoietic and nonhematopoietic cells (PD-L1) as well as on T Cell surface (PD-1). PD-L1/PD-1 interaction leads to 'T-Cell exhaustion" that consisted of impaired cytotoxic activity and decreased effector cytokine production resulting in immune-response inhibition.

Atezolizumab (MPDL3280A) is an engineered, humanised monoclonal IgG1 antibody, with a high affinity for PD-L1 acting as inhibitor of the interaction between PD-L1 and PD1/B7.1. It was the First immune agents who showed clinical activity in UC [9]. On the wave of the positive results obtained in phase I trial, a following phase II trial (IMvigor 210 trial, NCT02108652) with two different cohorts was performed (cohort 1, patients with metastatic urothelial cancers ineligible for platinum based chemotherapy for First line treatment; cohort 2, patients who progressed during or 
following platinum-based treatment). Regarding, Cohort $2(n=310)$, patients who received Atezolizumab showed an Objective Response Rate (ORR) of $15 \%$ and a 12-month OS of $37 \%$ in the overall population with a median duration of response not reached after a medium of 17.5 months of follow-up [10].

Results of Cohort $1(n=119)$ showed an ORR of $23 \%$ in the whole cohort with a median duration of response not reached at 14.4 months of follow-up and a median OS of 14.8 months (95\% CI 10.1 months to not reached) [11].

On the basis of the favourable results of the cohort 2, Atezolizumab has been approved by FDA for the treatment of patients with locally advanced or metastatic UC who have progressed during or following platinum-based chemotherapy or whose disease has worsened within 12 months neoadjuvant or adjuvant platinum-based chemotherapy.

Despite these remarkable results, more recently Powees et al recently presented preliminary results of IMvigor211. This was a randomized phase III trial of Atezolizumab compared to chemotherapy (docetaxel, paclitaxel and vinflunine) in patients progressed to platinum based therapy. Surprisingly Atezolizumab failed to show an improvement in Overall Survival in overall population (8.6 vs 8.0 months for Atezolizumab and chemotherapy respectively, HR 0.85) and in patients with high PDL1 expression (11.6 vs 10.6 months, HR 0.87) [12].

Pembrolizumab (MK-3475) is a humanized monoclonal IgG4 antibody against PD-1, which showed to be a safety and active treatment in a phase I basket trial involving also patients with UC [13]. Thanks to the positive results obtained in this study Pembrolizumab has been compared to standard second line chemotherapy in a large phase III clinical trial (Keynote 045) [14]. In this study 542 patients with locally advanced or metastatic predominantly transitional UC, progressed to First line platinum regimens or with recurrence disease within 12 months after adjuvant or neoadjuvant platinum containing therapy, were randomized (1:1) to receive Pembrolizumab $200 \mathrm{mg}$ every 3 weeks (Q3W) or chemotherapy (paclitaxel $175 \mathrm{mg} / \mathrm{m} 2 \mathrm{Q} 3 \mathrm{~W}$ or docetaxel $75 \mathrm{mg}$ Q3W or Vinfluine $320 \mathrm{mg} / \mathrm{m} 2 \mathrm{Q} 3 \mathrm{~W})$. Results of this study showed a better OS for patients treated with 
Pembrolizumab in overall population (mOS 10.3 vs 7.4 months HR $0.73,95 \% \mathrm{CI}, 0.59-0.91, \mathrm{p}=$ 0.002) and in patients with high PD-L1 expression (mOS 8.0 vs 5.2 months HR 0.57, 95\% CI, 0.370.88, $\mathrm{p}=0.0048$ ). No differences in terms of PFS have been found between the two arms. ORR as assessed on the intention to treat population) was significantly better in Pembrolizumab arm (21.1 $\%$ vs $11.4 \%)$ with a duration of response not reached (1.6 - 15.6+ months).

Partial results of the still ongoing phase II KEYNOTE 052 trial seems to confirm this positive results also when Pembrolizumab is adopted as First line therapy in platinum unfit patients with UC [15].

Nivolumab (MDX 1106) is a fully human IgG4 monoclonal antibody against PD-1 that has been approved for treatment of advanced melanoma, Hodgkin lymphoma, non-small cell lung cancer, head and neck cancer, and renal cell cancer. In UC it showed to be an active and safety treatment in phase I and II studies [16,17]. As observed with Nivolumab also the PD-L1 inhibitors Avelumab (MSB0010718C) and Durvalumab (MEDI4736) showed promising activity in phase I/II clinical trials in patients with UC suggesting the development of further clinical trials exploring these agents in different setting of UC [18-21]. The CTLA-4 receptor also known as CD156 is a member of the immunoglobulin superfamily and a transmembrane receptor expressed exclusively on T cells. The activation of CTLA-4 happened through interaction with CD80 and CD86 on antigen presenting cells and leads to a down-regulation of $\mathrm{T}$ helper lymphocyte and enhanced regulatory $\mathrm{T}$ cell immunosuppressive activity resulting in immune response inhibitor signal [22].

Ipilimumab is a CTLA-4 inhibitor that showed in a small clinical trial to be a safety preoperative treatment in patients with bladder UC [23].

On the basis of the positive outcome obtained it seems clear that the treatment paradigm of UC is about to change. The demonstration that immunotherapy could led to long term responses in different setting of UC and the safety profile showed in different clinical trials have move the development of several studies exploring these agents. This has led to in a complex scenario that will profoundly change the management of the disease. In the next paragraphs we will describe the 
ongoing and active clinical trials exploring these agents in different setting of the disease. In table 1 and table are summarized the phase III and phase I, I/II, II descripted in this manuscript.

\section{PD-1 AND PD-L1 INHIBITORS}

On the wave of the positive outcome obtained previously descripted clinical trials PD-1 inhibitors: Pembrolizumab and Nivolumab as well as the PD-L1 inhibitors: Atezolizumab, Avelumab and Durvalumab are being tested individually in different clinical trials and in different stages of the disease.

Regarding preoperative setting Pembrolizumab is being tested in a phase II trial enrolling 90 patients with muscle invasive bladder UC (T2-T4 N0) with residual disease after transurethral resection (NCT02736266). Patients enrolled will receive 3 cycles of Pembrolizumab (200 mg Q3W) before planned cystectomy with primary endpoint: pathological complete response rate. Another phase II trial is currently exploring the role of Atezolizumab as preoperative treatment in patients with T2-T4a urothelial bladder cancer (NCT02662309). Of note primary endpoints of this studies are the pathological complete response rate (pCRR, defined as $\geq 20 \%$ reduction in residual disease of the bladder based on histological evaluation of the resected bladder specimen collected during cystectomy post-treatment) and the dynamic changes in T cell subpopulations (CD8 and/or CD3) measured in tumour samples collected pre- and post-treatment.

Immune-checkpoint inhibitors are also under investigation in early stage of the disease. Indeed, a phase II trial (NCT02625961) will test Pembrolizumab in 260 patients with high risk non muscle invasive bladder cancer (high risk Ta, T1, carcinoma in situ) refractory to Bacillus Calmette-Guerin (BCG) therapy with primary endpoints: Disease Free Survival (DFS) and pCRR. Furthermore, another phase II trial is currently exploring the role of Atezolizumab in patients with high-grade urothelial bladder cancer refractory to BCG (NCT02844816).

Pembrolizumab and Avelumab are being tested as maintenance therapy after platinum-containing first line therapy. The phase III trial JAVELIN Bladder 100 study (NCT02603432) is currently 
ongoing to compare maintenance treatment with Avelumab plus best supportive care (BSC) versus BSC alone in metastatic UC patients who have not progressed during or following First-line systemic therapy. Primary endpoint is OS and approximately 668 patients are planned to be enrolled. This study will be completed in July 2019. The phase II trial (NCT02500121) is currently testing Pembrolizumab as maintenance therapy after standard First line chemotherapy in patients with locally advanced or metastatic UC. This study has 6-months PFS as primary endpoint and planned an enrolment of 200 patients with stable disease (SD), complete response (CR) or partial response (PR) after platinum-based first-line that will be randomized to receive Pembrolizumab or placebo.

Regarding adjuvant setting a large randomized phase III trial is testing Nivolumab as postoperative treatment in patients with high-risk invasive urothelial carcinoma (NCT02632409). The planned enrolment of this placebo controlled is 640 patients with primary endpoint DFS. The study started in February 2016 with estimated primary completion date in October 2020. The phase III (NCT02450331) is evaluating the different DFS in 700 patients with histologically confirmed muscle invasive urothelial carcinoma of the bladder or upper urinary tract. In this study patients will be randomized to receive Atezolizumab (1200 mg Q3W for 16 cycles) or observation. The planned completion date is estimated in April 2022.

Regarding first-line therapy Atezolizumab and Pembrolizumab are being tested in phase II clinical trials in patients unfit or refuising platinum based therapy (NCT02451423, Keynote 052). Of note preliminar results of Keynote 052 study seams to show an interesting ORR on the analysis of the first 100 patients enrolled (ORR: 24\%) [15].

An ongoing phase III trial (NCT02516241; DANUBE) of Durvalumab as a monotherapy or combined with Tremelimumab (CTLA4 inhibitor) versus standard-of-care chemotherapy (gemcitabine plus cisplatin or gemcitabine plus carboplatin) is currently recruiting patients with metastatic or unresectable UC. This 3-arm trial is expected to be completed in 2019 and OS is the primary endpoint. 


\section{EHNANCING IMMUNOTHERAPIES THROUGH COMBINATION STRATEGIES}

As already discussed, not all subjects respond to immune-checkpoint inhibitors and so the development of new strategies aimed to increase the number of patients who can benefit from these treatments it's strictly required.

There are several evidences showing that previously inflamed tumour could more benefit from immune-checkpoints inhibitors while "no-T cell inflamed tumours" not [24-26]. Tumours adopt several mechanisms through which became 'invisible' to immune cells. The absence of priming signals, the activation of tolerance signals by suppressive cytokines or recruitment of regulatory $\mathrm{T}$ cells, the absence of antigens or the absence of antigen presenting cells and the stromal interactions are possible strategies adopted by cancer cells to escape from immune-pressure.

The combination between immune-checkpoint inhibitors and other drugs could be a key option able to overcome the tumour immune escape. To date, several trials are testing different combination strategies with immune-checkpoint inhibitors and target agents, chemotherapy, radiotherapy, other immune agents and other immune-checkpoint inhibitors (Figure 1) to overcome the immune tumour resistance and improve clinical outcome in patients with urothelial carcinoma.

\subsection{PD-1/PD-L1 and CTLA-4 inhibitors combination}

As already descripted, PD-L1/PD-1 and CTLA-4 inhibitors adopt a different mechanism to enhance immune response against tumours. Indeed, inhibition of PD-L1/PD-1 pathway lead to a restored activity of pre-activated exhausted T cells while inhibition of CTLA-4 receptors resulting in an effector T Cell amplification in early stages of antigen presentation. As these are different pathway of a common cascade resulting in T Cell activation, a dual immune-checkpoint blockade could be a key option that would allow reaching better clinical outcome than PD-L1/PD-1 or CTLA-4 
monotherapy. This combination strategy has been already tested in melanoma with significant improvement of long-term responses compared to single agent monotherapy [27,28]. The Nivolumab and Ipilimumab combination is currently being tested in a large randomized clinical trial where patients with untreated metastatic or unresectable UC will be randomized to receive the immune checkpoints combination or platinum based chemotherapy (NCT03036098; CheckMate 901). The estimated enrolment of this trial is 690 patients with PFS and OS as primary endpoint. Another large phase II clinical trial (NCT01928394) is currently comparing the Nivolumab and ipilimumab association to Nivolumab monotherapy in patients with advanced triple-negative breast cancer, gastric cancer, pancreatic adenocarcinoma, small cell lung cancer, bladder cancer, and ovarian cancer.

Another phase III clinical trial (NCT03084471; STRONG) is currently comparing the combination Durvalumab-Tremelimumab to Durvalumab monotherapy in advanced solid malignancies with an estimated enrolment of 1200 patients. The aim of this study is to evaluate the safety profile of the combination immunotherapy with an estimated completion data in April 2022. Of note, the combination of Durvalumab with Tremelimumab is under investigation also in patients with muscle-invasive, high-risk UC who are ineligible for cisplatin-based neoadjuvant chemotherapy (NCT02812420).

\subsection{Immune-checkpoint inhibitors and other immune agents}

Another interesting strategy aimed to enhance the therapeutic potential of immune-checkpoint inhibitors consists of a combination between these agents and other able to increase the tumour associated immune-stroma. BCG instillation is able to induce an immune response against tumour cells and it's currently approved in early stage of urothelial bladder cancer with high risk of recurrence after local resection [29]. The association between BCG acting as an immune cells recruiter and the PD-1 inhibitor Pembrolizumab and PD-L1 inhibitor Atezolizumab is currently 
being explored in early stage of high risk UC (NCT02324582, NCT02808143 with Pembrolizumab and NCT02792192 with Atezolizumab).

Since activated-T Cells are the target of PD-1/PD-L1 inhibitors another approach is to increase the number of these cells. Indeed, tumours with low mutational load are associated with lower expression of cancer associated antigen/neo-antigen leading to small or absent tumour associated immune-infiltrate and lower activated T-Cells and Memory T-Cells resulting in a PD-1/PD-L1 and CTLA-4 inhibition escape [30-36]. The combination therapy with immune-checkpoint inhibitors and vaccines or tumour associated lymphocytes could help the recruitment of activated T-Cells and Memory T-Cells and it is currently being tested in phase I and phase II clinical trials in patients with advanced or recurrent malignancies including also UC (NCT02432963, NCT01174121) and as adjuvant treatment in patients with melanoma, lung or bladder cancer (NCT02897765).

Another strategy working in this way consists of the association between immune checkpoint inhibitors with cytokines able to enhance T-Cell activity. Interferon $\alpha$ increases dendritic cells functions and promotes $\mathrm{T}$ Cell activation showing a promising activity when associated to the CTLA-4 inhibitor Tremelimumab in patients with stage IV melanoma [37]. The association of Nivolumab and interferon $\alpha$ is currently being tested in patients with advanced solid tumours including also patients with UC (NCT02614456). The fusion protein NHS-IL 12 is composed of two molecules of IL-12 fused to a tumour necrosis-targeting IgG1 (NHS76). It has shown promising anti-tumour activity in murine tumour models [38]. The safety of the combination between the anti-PD L1 Avelumab and NHS-IL 12 is under investigation in a phase I clinical study (NCT02994953). The combination therapy between Durvalumab and Tremelimumab in association with polyICLC, a ligand of toll like receptor-3, is under investigation in patients with biopsy accessible solid tumours (NCT02118337).

The association between PD-L1 and PD-1 inhibitors is another option under investigation. Indeed, an ongoing phase 1 open-label (NCT02118436), dose-escalation and expansion study is recruiting patients with relapsed/refractory advanced solid malignancies to receive Durvalumab in 
combination to MEDI0680, a humanized IgG4 $\kappa$ monoclonal antibody specific for human PD-1 that blocks interaction with PD-L1 and programmed cell death ligand-2 (PD-L2). Of note, preliminary results showed a $15 \%$ ORR and a 35\% DCR. The most common drug-related adverse events were pruritus $(17 \%)$, fatigue (13\%), diarrhoea (13\%), flushing (10\%), peripheral edema (10\%) and pyrexia (10\%) [39].

\subsection{Immune-checkpoint inhibitors and oncolytic viruses}

Oncolytic viruses are novel promising agents against cancer. These modified viruses could be directed against specific targets, perform a lytic effect on tumour cells and act as immune stimulators $[40,41]$. Thanks to these proprieties, oncolytic viruses are currently testing in several clinical trials. Regarding UC, CA21 and enadenotucirev are currently under evaluation. The oncloytic coxsackievirus CA 21 target the Intercellular Adhesion Molecule I (ICAM-1) on tumour cells surface. It has already showed promising activity in melanoma as well as in non muscular invasive bladder cancer $[42,43]$. To date the safety of combination between pembrolizumab and CA21 in advanced or recurrent tumours is being evaluated in phase I clinical trial (NCT02043665). Enadenotucirev is an oncolytic group B adenovirus able to replicate in cancer cells leading to their lysis. It showed a safety profile in patients with metastatic epithelial cancer [44] and is currently tested with Pembrolizumab in metastatic solid tumours (NCT02636036).

\subsection{Immune-checkpoint inhibitors combination and chemo/radio therapy}

Radiotherapy and chemotherapy could play a key role as agents able to overcome immune-tumour escape. Indeed, tumour irradiation stimulates an intensive inflammation in the site of application, promotes the production of adhesion molecules and MHC I and activates an intensive flux of CD8+ lymphocytes. Through these mechanisms irradiation drives an immune response that leads also to 
the regression of distant and un-irradiated tumour lesions (Abscopal effect) [45,46]. Not surprising, immune-checkpoint therapy combination with tumours irradiation represents an emerging strategy with a strong biological rational [46,47]. Several phase I/II clinical trials are exploring the association between Pembrolizumab and radiation therapy with (NCT02662062, NCT02621151) or without (NCT02560636) chemotherapy in different stage of the disease. Among them, a phase I-II study led by Sundahl et al. is exploring the efficacy and safety of fixed-dose stereotactic body radiotherapy with sequential or concurrent Pembrolizumab in patients with metastatic UC [48]. On the other hand, the association between Durvalumab and radiation therapy is under investigation as adjuvant treatment in a phase I/II trial (NCT02643303).

Chemotherapy has represented the standard therapy for metastatic or locally advanced unresectable UC and it's likely that it will play an important role also in association with immune-checkpoints inhibitors. There are several proposed mechanisms through which chemotherapy could overcome immune-tumour escape. First the lytic effect done by antiblastic agents could lead to the presentation of antigen and neo-antigen resulting in T-Cell activation. Second, through the elimination of immunosuppressive cells could restore immune activity against tumours. Third, it could drive a better penetration of immune cells in tumour stroma. Furthermore, there are evidences that patients who received chemotherapy after immune treatment could have a better response to antiblastic agents suggesting a synergic effect between chemotherapy and immune-therapy [49,50]. This approach is currently investigated by several clinical trials in UC. Of note, two phase III clinical trials are exploring the association between Pembrolizumab or Atezolizumab and chemotherapy. The KEYNOTE 361 (NCT02853305) is a phase III randomized clinical trial with an estimated enrolment of 990 patients with metastatic or locally advanced UC who will be randomized to receive Pembrolizumab (200 mg every 3 weeks) with or without platinum based chemotherapy or chemotherapy alone. PFS and OS are primary endpoints with estimated primary completion data expected in March 2019 and study completion data in April 2020. 
The IMvigor130 (NCT02807636) is a randomized placebo-controlled phase 3 clinical trial where 1200 patients with metastatic or locally advanced unresectable urothelial cancer will be randomized to receive Atezolizumab (1200 mg every 3 weeks) alone or in combination with platinum based chemotherapy. Patients enrolled in comparator arm will receive standard platinum based chemotherapy with placebo. This study will test safety and the clinical efficacy of Atezolizumab monotherapy or combination with primary endpoints PFS, OS and adverse events rate. The estimated primary completion data is expected in December 2018 while the completion of study in July 2020.

\subsection{Immune checkpoint inhibitors combination with target therapy}

No targeted therapy as well as no anti-angiogenic agents have shown significant clinical results in patients with UC. Nonetheless, the combination between immune-checkpoints inhibitors and target agents is under investigation in several phase I/II clinical trials. The rational of this association resides in the hypothesis that inhibition of specific and altered pathway leads to a better response to immunotherapy. Indeed, the inhibition of key signalling such as VEGF (Vascular Endothelial Growth Factor), FGF (Fibroblastic Growth Factor), MET (Mesenchimal-Epithelial Transition) could led to the direct exposure of tumour cells to immune cells, to a reduction of regulatory immune cells and finally to tumour cell lysis with expression of antigen and neoatingen $[51,52]$.

Regarding angiogenesis inhibitors, the VEGFR-2 (Vascular Endothelial Growth Factor Receptor 2) inhibitor Ramucirumab and the anti-VEGF Bevacizumab are currently being tested in combination with Pembrolizumab (NCT02443324) and Atezolizumab (NCT01633970) in patients with advanced solid tumours including also patients with advanced UC. Levatinib is a VEGFR1, VEGFR2 and VEGFR3 kinase inhibitor that is under investigation in combination with Pembrolizumab in a phase I (NCT03006887) and a phase I/II clinical trials (NCT02501096). EphB4-HAS is a recombinant fusion protein composed of the extracellular domain of the human 
receptor tyrosine kinase ephrin type-B receptor 4 (sEphB4) and human serum albumin (HSA). This protein acts interfering the binding of Ephirin b2 (Efnb2) to the Ephrin B4 and A3 receptors (EphB4 and EphA3), resulting in angiogenesis inhibition in tumour cells overexpressing Efnb2 and EphB4. The combination between Pembrolizumab and EphB4-HAS protein is currently being tested in a phase II trial evaluating the clinical activity of this association in previously treated patients with locally advanced or metastatic UC (NCT02717156).

About drugs targeting specific target of the tumour related stroma, the VEGFR 1-3, FGFR 1-3 (Fibroblastic Growth Factor Receptor 1-3), PDGFR- $\alpha$ (Platelet-Derived Growth Factor Receptor $\alpha$ ) inhibitor Nintedanib and the FGFR-3 inhibitor B-701 are currently under investigation in combination with Pembrolizumab in two phase I studies (NCT02856425, NCT02925533). INCB054828 is an orally bioavailable inhibitor of FGFR 1-3. A phase I/II trial (NCT02393248) enrolling patients with advanced solid tumour is comparing the activity of INCB054828 in association with Pembrolizumab or with chemotherapy (Gemcitabine + cisplatin or docetaxel).

Pexidartinib (PLX3397) is an interesting tyrosine-kinase inhibitor of the stem cell factor receptor (KIT), colony-stimulating factor-1 receptor (CSF1R) and FMS-like tyrosine kinase 3 (FLT3). These pathways play a key role in tumour proliferation and macrophages, osteoclasts and mast cells downmodulation resulting in stimulation of osteolytic metastatic process. The Pembrolizumab and PLX3397 combination is under evaluation in a phase I/II clinical trials enrolling patients with advanced solid tumours (NCT02452424).

The safety profile of the combination between Nivolumab and the MET and VEGFR2 kinases inhibitor cabozantinib is under investingation in a phase I study (NCT02496208) in 113 patients with locally advanced or metastatic genitourinary tumours.

The phase Ib NCT02546661 is a randomised multi-drug trial testing the PD-L1 inhibitor Durvalumab, the nuclear enzyme poly (ADP-ribose) polymerase (PARP) Olaparib, the mammalian target of rapamycin (mTOR) inhibitor Vistusertib, the FGFR inhibitor AZD4547 and the WEE1 tyrosine kinase inhibitor AZD1175. 
This study is evaluating the safety profile of these association and has an estimated enrollment of 110 patients with muscle invasive bladder cancer progressed on prior treatment who will be randomized to receive: AZD4547, Durvalumab with AZD4547, Durvalumab with Olaparib, Durvalumab with AZD1775, Durvalumab with Vistusertinib or Durvalumab monotherapy. Another interesting agent under inverstigation is Vorinostat that is a compound able to bind the catalytic domain of the histone deacetylases resulting in accumulation of hyperacetylated histones and trascription factors [53]. Hyperacetylation of hystone results in upregulation of cyclindependant kinase p21 and in a G1 arrest of the cell cycle. Furthermore, hyperacetylation of nonhistone proteins such as p53, alpha tubulin and heat-shock protein 90 leads to an additional antiproliferative effect. A phase I/II study is evaluating the safety profile and the clinical activity of the association between Pembrolizumab and Vorinostat in previously treated patients with advanced or metastatic renal cell carcinoma and UC (NCT02619253).

\section{OTHER IMMUNOLOGICAL APPROACH}

Interleukin-15 is a cytokine who plays a key role in activation, development and proliferation of CD8+ Memory T cells and natural killer cells. ALT-803 is a IL-15 mutant able to enhance IL-15 activity that has demonstrated safety and promising anti-tumour activity in solid and haematological tumour models [54,55]. Several trials are currently testing this agent in combination with BCG in high risk not muscle invasive bladder cancer (NCT03022825, NCT02138734).

ALT-801 is a novel immunotherapeutic fusion protein composed of interleukin-2 linked to a single chain $\mathrm{T}$ cell receptor domain who has already shown to be a safety and active treatment against solid and haematological malignancies [56,57]. Furthermore, ALT-801 has been tested with platinum based chemotherapy in patients with advanced or metastatic UC showing an interesting ORR $(35 \%)$ burdened by a significant toxicity (50\% of patients with Grade 3-4 adverse related events) [58]. Future trials will explore the role of this agent in UC (NCT01625260, NCT01326871). 
CD137 is a costimulatory member of the TNF (Tumour Necrosis Factor) receptor superfamily that is expressed on T Cells, dendidritc cells and natural killer cells after antigen mediated activation. CD137 activation results in cytokine induction and stimulated activity of T-Cells leading to an enhanced immune-response against tumour cells [59,60]. Urelumab (BMS-663513) is a fully human IG4 antibody able to blind and agonist CD137 receptor has already been tested in small phase I clinical studies showing a safety profile [61]. A phase II clinical trial (NCT02845323) will compare this combination treatment to Nivolumab monotherapy as neo-adjuvant treatment in patients unfit to Cisplatin standard therapy.

CD27 is another costimulatory receptor member of the TNF receptor superfamily. CD27, which through the interaction with its ligand (CD70), plays an important role in generation and maintenance of immune response especially through B-Cell activation and immunoglobulin synthesis [62]. Varlilumab is a human monoclonal antibody with agonistic activity to CD27 receptor that is currently testing with Atezolizumab in a phase I clinical trial exploring the safety profile and the clinical activity of this combination (NCT02543645) [63] .

B7-H3 belongs to B7 superfamily and acts a costimulatory molecule who leads after itself stimulation to a down-modulation of T-Cell activation [64] This molecule has been recently associated with specific immune-pathways and poor clinical outcome in prostate cancer [65]. Enoblituzumab (MGA 271) is a humanized monoclonal antibody targeting B7-H3. Association between Enoblituzumab and Pembrolizumab (NCT02475213) or Ipilimumab (NCT02381314) is currently exploring the safety of these agents in advanced or metastatic malignancies including UC. MGD009 is a protein targeting B7-H3 and CD3 who redirects CD3 expressing T Cell to kill B7-H3 expressing cells. Currently, MGD009 safety profile is under investigation in a phase I clinical trial in patients with advanced solid tumours, including also patients with bladder cancer (NCT02628535).

Acalabrutinib is an orally available inhibitor of Bruton's tyrosine kinase (BTK). BTK plays a key role in lymphocites B activation and proliferation and is generally overexpressed in B-cell 
malignancies. The clinical activity of the association between Acalabrutinib (ACP-196) and Pembrolizumab compared to Pembrolizumab monotherapy is currently under investigation in a phase II clinical trial (NCT02351739).

CM-24 is a humanized monoclonal immunoglobulin targeting the anti-carcinoembyonic antigen (CEA)-related cell adhesion molecule 1 (CEACAM 1). This adhesion molecule is expressed on the surface of tumour cells as well as on the surface of several immune cells and its inhibition leads to an enhances activation of cytotoxic T-Lymphocytes and natural killer cells [66]. A phase I trial is evaluating the safety profile of the association between Pembrolizumab and CM-24 in patients with advanced solid tumours (NCT02346955).

The IDO (indoleamine 2,3-dioxygenase) catalyzes the cleavage of L-Tryptophan resulting in the production of kynurenine. The accumulation of kynurenine as well as the depletion of tryptophan resulting in an increased numbers of $\mathrm{T}$ regs lymphocyte leading to a reduction of active and effector T cells [67]. Epacadostat is an IDO inhibitor which is currently testing in several solid tumours in combination with CTLA-4 and PD-1 inhibitors. Phase I and II clinical trials are currently exploring the safety profile of the combination therapy between Durvalumab and Epacadostat (NCT02318277) as well as Atezolizumab and Epacadostat (NCT022981539).

There are further evidences that the depletion of arginine in arginase-expressing myeloid cells leads to an inhibition of proliferation and activity of lymphocytes resulting in an immune-response inhibition [68]. To overcome the immunosuppressive effect caused by arginine depletion a human arginases inhibitor has been developed. A phase I trial (NCT02903914) is currently testing the safety profile of the arginases inhibitor CB-1158 alone or in combination with Nivolumab in 236 patients with advanced solid malignancies including UC.

The adenosine A2A receptor also known as ADORA2A is an adenosine receptor expressed basal ganglia, vasculature, and platelets. Several immune cells like macrophages, dendritic cells, natural killer cells and T-lymphocites expressed this receptor whose activation leads to an inhibition of the immune response [69]. CPI-444 is a small molecule that acts as an antagonist of Adenosine A2A 
receptor. It's safety profile in combination with Atezolizumab is currently under investigation in patients with advanced solid tumours including also patients with UC (NCT02655822).

\section{FUTURE PERSPECTIVES}

Chemotherapy has represented the standard treatment for locally advanced and metastatic UC but this scenario is about to change. The important results achieved suggesting that immunotherapy will probably be the future treatment paradigm of the disease. Immune-checkpoint inhibitors represent a realistic hope for patients with UC. Indeed, they appear to significantly improve the overall survival of these patients and thanks to a better safety profile compared to chemotherapy they could be proposed also in patients with poor clinical features.

Future trial will explore the role of immune-checkpoint inhibitor in other setting of the disease including: early stages, pre-operative and adjuvant setting and their efficacy as First line treatment. Furthermore, another issue to be explored is whether combination between immune-checkpoint inhibitors and other agents including other immune-agents, target drugs, oncolytic viruses, chemotherapy and radiotherapy leads to a high percentage of patients who can benefit from immunotherapy. The possibility that several patients could obtain stable and durable response have lead to the development of several clinical trials exploring different kind of combination between these agents boosting a revolution that has just begun.

\section{CONCLUSION}

Chemotherapy has represented the standard treatment for locally advanced and metastatic urothelial carcinoma but this scenario is about to change. The important results achieved suggesting that immunotherapy will probably be the future treatment paradigm of the disease. Immune-checkpoint inhibitors represent a realistic hope for patients with UC. Indeed, they appear to significantly improve the overall survival of these patients and thanks to a better safety profile compared to chemotherapy they could be proposed also in patients with poor clinical features. 
Future trial will explore the role of immune-checkpoint inhibitor in other setting of the disease including: early stages, pre-operative and adjuvant setting and their efficacy as First line treatment. Furthermore, another issue to be explored is whether combination between immune-checkpoint inhibitors and other agents including other immune-agents, target drugs, oncolytic viruses, chemotherapy and radiotherapy leads to a high percentage of patients who can benefit from immunotherapy. The possibility that several patients could obtain stable and durable response have lead to the development of several clinical trials exploring different kind of combination between these agents boosting a revolution that has just begun.

Conflicts of interest: The authors declare no conflict of interest with the contents of this work.

Financial disclosures: This research did not receive any specific grant from funding agencies in the public, commercial, or not-for-profit sectors. 


\section{References}

[1] Torre LA, Bray F, Siegel RL, et al. Global cancer statistics, 2012. CA Cancer J Clin 2015; 65:87.

[2] von der Maase H, Sengelov L, Roberts JT, Ricci S, Dogliotti L, Oliver T et al. Long-term survival results of a randomized trial comparing gemcitabine plus cisplatin, with methotrexate, vinblastine, doxorubicin, plus cisplatin in patients with bladder cancer. $J$. Clin. Oncol. 2005;20, 23(21): 4602-4608.

[3] De Santis M, Bellmunt J, Mead G, Kerst JM, Leahy M, Maroto P et al. Randomized phase II/III trial assessing gemcitabine/carboplatin and methotrexate/carboplatin/vinblastine in patients with advanced urothelial cancer who are unfit for cisplatin-based chemotherapy: EORTC study 30986. J. Clin. Oncol. 2012;10,30(2): 191-199.

doi: 10.1200/JCO.2011.37.3571.

[4] Galsky MD, Chen GJ, Oh WK, Bellmunt J, Roth BJ, Petrioli R et al. Comparative effectiveness of cisplatin-based and carboplatin-based chemotherapy for treatment of advanced urothelial carcinoma. Ann. Oncol. 2012;23(2): 406-410.

doi: 10.1093/annonc/mdr156.

[5] Locke JA, Pond GR, Sonpavde G, Necchi A, Giannatempo P, Paluri RK et al. Efficacy and Safety of Gemcitabine Plus Either Taxane or Carboplatin in the First-Line Setting of Metastatic Urothelial Carcinoma: A Systematic Review and Meta-Analysis. Clin. Genitourin. Cancer. 2016;14(4): 331-340.

doi: 10.1016/j.clgc.2015.10.005. 
[6] Raggi D, Miceli R, Sonpavde G, Giannatempo P, Mariani L, Galsky MD et al. Second-line single-agent versus doublet chemotherapy as salvage therapy for metastatic urothelial cancer: a systematic review and meta-analysis. Ann. Oncol.2016; 27(1): 49-61. doi: 10.1093/annonc/mdv509.

[7] Bellmunt J, Fougeray R, Rosenberg JE, von der Maase H, Schutz FA, Salhi Y et al. Longterm survival results of a randomized phase III trial of vinflunine plus best supportive care versus best supportive care alone in advanced urothelial carcinoma patients after failure of platinum- based chemotherapy. Ann. Oncol. 2013;24(6): 1466-1472. doi: 10.1093/annonc/mdt007.

[8] Lawrence MS, Stojanov P, Polak P, Kryukov GV, Civulskis K, Sivachenko A et al. Mutational heterogeneity in cancer and the search for new cancer-associated genes. Nat. 2013;11, 499(7457): 214-218.

doi: 10.1038/nature12213.

[9] Powles T, Eder JP, Fine GD, Braiteh FS, Loriot Y, Cruz C et al. MPDL3280A (anti-PD-L1) treatment leads to clinical activity in metastatic bladder cancer. Nat. 2014; 515(7528): 558562.

doi: 10.1038/nature13904.

[10] Rosenberg JE, Hoffman-Censits J, Powles T, van der Heijeden MS, Balar AV, Necchi A et al. Atezolizumab in patients with locally advanced and metastatic urothelial carcinoma who have progressed following treatment with platinum-based chemotherapy: a single-arm, multicentre, phase 2 trial. Lancet. 2016; 387: 1909-1920. 
doi: 10.1016/S0140-6736(16)00561-4.

[11] Balar AV, Galsky MD, Rosenberg JE, Powles T, Petrylak DP, Bellmunt J et al. Atezolizumab as first line treatment in cisplatinineligible patients with locally advanced andmetastatic urothelial c arcinoma: a single-arm, multicentre, phase 2 trial. Lancet. 2017; 7, 389(10064): 67-76. doi: 10.1016/S0140-6736(16)32455-2.

[12] Powles T, Loriot Y, Durán I, et al. IMvigor211: A Phase III Randomized Study Examining Atezolizumab Versus Chemotherapy for Platinum-Treated Advanced Urothelial Carcinoma. Presented at the 2nd Special Conference EACR-AACR-SIC, Florence, Italy, June 24-27, 2017

[13] Plimack ER, Bellmunt J, Gupta S, Berger R, Chow LQ, Juco J et al. Safety and activity of pembrolizumab in patients with locally advanced or metastatic urothelial cancer (KEYNOTE-012): a non-randomised, open-label, phase 1b study. Lancet Oncol. $2017 ; 18(2): 212-220$.

doi: 10.1016/S1470-2045(17)30007-4.

[14] Bellmunt J, de Wit R, Vaughn DJ, Fradet Y, Lee JL, Fong L et al. Pembrolizumab as Second-Line Therapy for Advanced Urothelial Carcinoma. N. Engl. J. Med. 2017;16, 376(11): 1015-1026.

doi: 10.1056/NEJMoa1613683. 
Pembrolizumab (pembro) as first-line therapy for advanced/unresectable or metastatic urothelial cancer: Preliminary results from the phase 2 KEYNOTE-052 study. Ann Oncol. 2016;27: Suppl 6. Abstract.

https://doi.org/10.1093/annonc/mdw435.25

[16] Sharma P, Callahan MK, Bono P, Kim J, Spiliopoulou P, Calvo E et al. Nivolumab monotherapy in recurrent metastatic urothelial carcinoma (CheckMate 032): a multicentre, open-label, two-stage, multi-arm, phase 1/2 trial. Lancet Oncol.2016;17(11):1590-1598. doi: 10.1016/S1470-2045(16)30496-X. in metastatic urothelial carcinoma after platinum therapy (CheckMate 275): a multicentre, single-arm, phase 2 trial. Lancet Oncol. 2017;18(3):312-322.

doi: 10.1016/S1470-2045(17)30065-7.

Boyerinas B, Jochems C, Fantini M, Heery CR, Gulley JL, Tsang KY et al. Antibody-dependent cellular cytotoxicity activity of a novel anti-PD-L1 antibody avelumab (MSB0010718C) on human tumor cells. Cancer Immunol. Res. 2015;3:1148-1157.

doi: 10.1158/2326-6066.CIR-15-0059.

[19]

M.R. Patel, J. Ellerton, M. Agrawal, M Gordon, L Dirix, K-W Lee et al: Avelumab (MSB0010718C; anti-PD-L1) in patients with metastatic urothelial carcinoma progressed after platinum-based therapy or platinum ineligible. Ann. Oncol. 2016;27 (6):266-295. https://doi.org/10.1093/annonc/mdw373.05 

patients with metastatic urothelial carcinoma from the JAVELIN solid tumor phase $1 \mathrm{~b}$ trial: Analysis of safety, clinical activity, and PD-L1 expression. J. Clin. Oncol. 2016;34, suppl; abstr 4514.

Massard C, Gordon MS, Sharma S, Rafili S, Wainberg ZA, Luke J et al. Safety and efficacy of durvalumab (MEDI4736), an anti-programmed cell death ligand-1 immune checkpoint inhibitor, in patients with advanced urothelial bladder cancer. J. Clin. Oncol. 2016;34(26): 3119-3125.

doi: 10.1200/JCO.2016.67.9761.

[22] Pardoll DM. The blockade of immune checkpoints in cancer immunotherapy. Nat. Rev. Cancer. 2012;22,12(4):252-264.

doi: $10.1038 / \mathrm{nrc} 3239$.

[23] Carthon BC, Wolchok JD, Yuan J, Kamat A, Ng Tang DS, Sun J et al. Preoperative CTLA-4 blockade: tolerability and immune monitoring in the setting of a presurgical clinical trial. Clin. Cancer. Res. 2010;15, 16(10):2861-2871.

doi: 10.1158/1078-0432.CCR-10-0569.

[24] Chen PL, Roh W, Reuben A, Cooper ZA, Spencer CN, Prieto PA et al. Analysis of immune signatures in longitudinal tumor samples yields insight into biomarkers of response and mechanisms of resistance to immune checkpoint blockade. Cancer. Discov. 2016;6(8):827-837.

doi: 10.1158/2159-8290.CD-15-1545. 
Nat. 2017;18,541(7637):321-330.

doi: 10.1038/nature21349.

Ott PA, Hodi FS, Kaufman HL, Wigginton JM, Wolchok JD. Combination immunotherapy: a road map. J. Immunother. Cancer. 2017;21: 5-16. doi: 10.1186/s40425-017-0218-5. Combined nivolumab and ipilimumab or monotherapy in untreated melanoma. $N$. Engl. J. Med. 2015;373(1):23-34. doi: 10.1056/NEJMoa1504030. Nivolumab and ipilimumab versus ipilimumab in untreated melanoma. N. Engl. J. Med. 2015;372(21):2006-2017. doi: 10.1056/NEJMoa1414428.

Long term efficacy results of EORTC genito-Urinary Group randomized phase 3 study 30911 comparing intravescical instillation of epirubicin, bacillus Calmette-guerin, and bacillus Calmette- Guerin plus isoniazid in patients with intermediate and high risk stage Ta T1 urothelial carcinoma of the bladder. Eur. Urol. 2010;57(5):247-256. doi: 10.1016/j.eururo.2009.12.024. 

immunology. Mutational landscape determines sensitivity to PD-1 blockade in non-small cell lung cancer. Sci. 2015; 348(6230):124-128.

doi: $10.1126 /$ science.aaa1348. blockade in tumors with mismatch-repair deficiency. N. Engl. J. Med. 2015;2, 372(26):2509-2520.

doi: 10.1056/NEJMoa1500596.

[32] Van Allen EM, Miao D, Schilling B, Shukla SA, Blank C, Zimmer L et al. Genomic correlates of response to CTLA-4 blockade in metastatic melanoma. Sci. 2015;350(6257):207-211.

doi: $10.1126 /$ science.aad0095.

[33] Schumacher TN, Schreiber RD. Neoantigens in cancer immunotherapy. Sci. $2015 ; 348(6230): 69-74$.

doi: $10.1126 /$ science.aaa4971.

[34] Zaretsky JM, Garcia-Diaz A, Shin DS, Escuin-Ordinas H, Hugo W, Hu-Lieskovan S et al. Mutations associated with acquired resistance to PD-1 blockade in melanoma. N. Engl. J. Med. 2016;375:819-829.

doi: 10.1056/NEJMoa1604958. 

immune monitoring for cancer immunotherapies in the era of checkpoint inhibition. Clin. Cancer. Res. 2016;22:1865-1874.

doi: 10.1158/1078-0432.CCR-15-1507.

[36] Vesely, M. D. \& Schreiber, R. D. Cancer immunoediting: antigens, mechanisms, and implications to cancer immunotherapy. Ann. NY Acad. Sci. 2013;1284: 1-5. doi: 10.1111/nyas. 12105 and efficacy of combination immunotherapy with interferon alfa- $2 b$ and tremelimumab in patients with stage IV melanoma. J. Clin. Oncol. 2012;30(3):322-328.

doi: 10.1200/JCO.2011.37.5394.

[38] Fallon J, Tighe R, Kradjian G, Guzman W, Bernhardt A, Neuteboom B et al. The immunocytokine NHS-IL12 as a potential cancer therapeutic. Oncotarget. 2014;15, 5(7):1869-1884.

Combination of MEDI0680, an anti-PD-1 antibody, with durvalumab, an anti-PD-L1 antibody: a phase 1, open-label study in advanced malignancies. Ann. Oncol. 2016;27, suppl 6, 1050PD. https://doi.org/10.1093/annonc/mdw378.05

[40] Kaufman HL, Kohlhapp FJ, Zloza A. Oncolytic viruses: a new class of immunotherapy drugs. Nat. Rev. Drug Discov. 2015;14(9):642-662. 
doi: $10.1038 / \mathrm{nrd} 4663$.

[41] Lawler SE, Speranza MC, Cho CF, Chiocca EA. Oncolytic Viruses in Cancer Treatment: A Review. JAMA Oncol. 2017;3(6):841-849. doi: 10.1001/jamaoncol.2016.2064.

E.L et al. Final data from CALM: a phase II study of Coxsackievirus A21 (CVA21) oncolytic virus immunotherapy in patients with advanced melanoma. J Clin Oncol. 2015;33, suppl, abstr 9030.

Nicola E Annels, Guy Simpson, Arif M, Denyer M, Iqbal A et al. Oncolytic immunotherapy for the treatment of non-muscle invasive bladder cancer using intravesical coxsackievirus A21. J. Immunother. Cancer. 2015; 3(2):331.

doi: 10.1186/2051-1426-3-S2-P331

[44] Calvo E, Gil-Martin M, Jean-Pascal H. M, Rottey S, Cubillo A, Salazar R et al. A first-in-class, first-in- human phase I study of enadenotucirev, an oncolytic Ad11/Ad3 chimeric group B adenovirus, administered intravenously in patients with metastatic epithelial tumors. J. Clin. Oncol. 2014;32 5s,suppl; abstr 3103. by antigen cascade after systemic tumor vaccination in combination with local tumor radiation. Cancer Biother. Radiopharm. 2012;27, 12-22.

doi: $10.1089 /$ cbr.2012.1202. 

Immunologic correlates of the abscopal effect in a patient with melanoma. N. Engl. J. Med. 2012;366, 925-931.

doi: 10.1056/NEJMoa1112824. Radiation and dual checkpoint blockade activate non-redundant immune mechanisms in cancer. Nat. 2015;520(7547):373-377.

doi: 10.1038/nature14292. al. A phase I/II trial of fixed-dose stereotactic body radiotherapy with sequential or concurrent pembrolizumab in metastatic urothelial carcinoma: evaluation of safety and clinical and immunologic response. J Transl Med. 2017 Jun 29;15(1):150. doi: $10.1186 / \mathrm{s} 12967-017-1251-3$ through selective inhibition of myeloid derived suppressor cells by anticancer therapies. Curr. Mol. Med. 2011;11:365-372. efficacy of chemotherapeutic regimens. Nat. Rev. Clin. Oncol.2011;8(3):151-160. by anticancer drugs. Nat. Rev. Drug Discov. 2012;11:215-233. 
doi: $10.1038 / \mathrm{nrd} 3626$.

[52]

Terme M, Pernot S, Marcheteau E, Sandoval F, Benhamouda N, Colussi O et al. VEGFA-VEGFR pathway blockade inhibits tumor-induced regulatory T-cell proliferation in colorectal cancer. Cancer Res. 2013;73, 539-549.

doi: 10.1158/0008-5472.CAN-12-2325.

$[53]$

Damaskos C, Garmpis N, Valsami S, Spartalis E, Antoniou EA, Tomos P et al. Deacetylase Inhibitors: A Novel Therapeutic Weapon Against Medullary Thyroid Cancer? Anticancer Res. 2016;(10):5019-5024.

Kim, P.S.; Kwilas, A.R.; Xu W, Alter S, Jeng EK, Wong HC Il-15 superagonist/IL15RalphaSushi-Fc fusion complex (IL-15Sa/IL-15RalphaSu-Fc; ALT-803) markedly enhances specific subpopulations of nk and memory CD8+ $\mathrm{T}$ cells, and mediates potent anti-tumor activity against murine breast and colon carcinomas. Oncotarget. 2016;7:1613016145.

doi: 10.18632/oncotarget.7470. Intravesical ALT-803 and bcg treatment reduces tumor burden in a carcinogen induced bladder cancer rat model; a role for cytokine production and nk cell expansion. PLoS ONE. 2014;9:96705.

doi: 10.1371/journal.pone.0096705. 
TCR/IL-2 fusion protein against established tumors. Cancer Immunol. Immunother. 2008;57:1781-1794.

doi: $10.1007 / \mathrm{s} 00262-008-0504-7$

Fishman, M.N.; Thompson, J.A.; Pennock, G.K, gonzalez R, Diez LM, Daud AI et al. Phase I trial of ALT-801, an interleukin-2/T-cell receptor fusion protein targeting p53 (aa264-272)/HLA-A*0201 complex, in patients with advanced malignancies. Clin. Cancer Res. 2011;17:7765-7775.

doi: 10.1158/1078-0432.CCR-11-1817.

[58]

Fishman, M.N.; Vaena, D.A.; Singh, Picus J, Ulka N.V, Slaton J et al. Phase Ib/II study of an IL-2/T-cell receptor fusion protein in combination with gemcitabine and cisplatin in advanced or metastatic chemo-refractory urothelial cancer (UC). J. Clin. Oncol. $2015 ; 33: 4515$.

Vinay DS, Kwon BS. 4-1BB (CD137), an inducible costimulatory receptor, as a specific target for cancer therapy. BMB Rep. 2014;47:122-129.

[60] Yonezawa A, Dutt S, Chester C, Kim J, Kohrt HE. Boosting cancer immunotherapy with anti-CD137 antibody therapy. Clin. Cancer Res. 2015;21:3113-3120. doi: 10.1158/1078-0432.CCR-15-0263.

[61] Segal NH, Logan TF, Hodi FS, McDermott D, Melero I, Hamid O et al.Results from an Integrated Safety Analysis of Urelumab, an Agonist Anti-CD137 Monoclonal Antibody. Clin. Cancer Res. 2017; 23(8): 1929-1936. 
doi: 10.1158/1078-0432.CCR-16-1272.

[62] van de Ven K, Borst J. Targeting the T-cell co-stimulatory CD27/CD70 pathway in cancer immunotherapy: rationale and potential. Immunot. 2015;7(6):655-667. doi: $10.2217 /$ imt.15.32.

[63] Ramakrishna V, Sundarapandiyan K, Zhao B, Bylesjo M, Marsh HC, Keler T. Characterization of the human $\mathrm{T}$ cell response to in vitro CD27 costimulation with varlilumab. J. Immunother. Cancer. 2015;18;3:37. doi: 10.1186/s40425-015-0080-2.

[64] Leitner J, Klauser C, Pickl WF, Stockl J, Majdic O, Bardet AF et al. B7-H3 is a potent inhibitor of human T-cell activation: No evidence for B7-H3 and TREML2 interaction. Eur J Immunol. 2009;39(7): 1754-1764.

doi: 10.1002/eji.200839028.

Benzon B, Zhao SG, Haffner MC, Taklhar M, Erho N, Yousefi K et al. Correlation of B7-H3 with androgen receptor, immune pathways and poor outcome in prostate cancer: an expression-based analysis. Prostate Cancer Prostatic Dis. 2017;20(1):28-35.

doi: $10.1038 /$ pcan.2016.49.

[66] Ling Y, Wang J, Wang L, Hou J, Qian P, Xiang-dong W. Roles of CEACAM1 in cell communication and signaling of lung cancer and other diseases. Canc. Met. Rev. 2015;34(2):347-357.

doi: 10.1007/s10555-015-9569-X. 
[67] Munn DH, Mellor AL. IDO in the Tumor Microenvironment: Inflammation, Counter-Regulation, and Tolerance. Trends Immunol. 2016;37(3):193-207. doi: 10.1016/j.it.2016.01.002.

[68] Geiger R, Rieckmann JC, Wolf T, Basso C, Feng Y, Fuhrer T et al. L-Arginine Modulates T Cell Metabolism and Enhances Survival and Anti-tumor Activity. Cell. $2016 ; 20,167(3): 829-842$.

doi: 10.1016/j.cell.2016.09.031.

[69] Sepúlveda C, Palomo I, Fuentes E. Role of adenosine A2b receptor overexpression in tumor progression. Life Sci. 2016;1,166: 92-99.

doi: $10.1016 /$ j.lfs.2016.10.008. 
[70]

\section{Table Legend}

Table 1. Ongoing phase III clinical trials with an immunotherapy agent in urothelial cancer.

Table 2. Ongoing phase II/III,II, I/II and I studies with immune-checkpoints inhibitors, CTLA-4 Inhibitors and other immuno agents.

OS: Overall Survival, PFS: Progression Free survival, CRR: Complite response rate, DFS: Disease Free Survival.

\section{Figure Legend}

Figure 1. Immunotherapeutic approaches in bladder cancer.

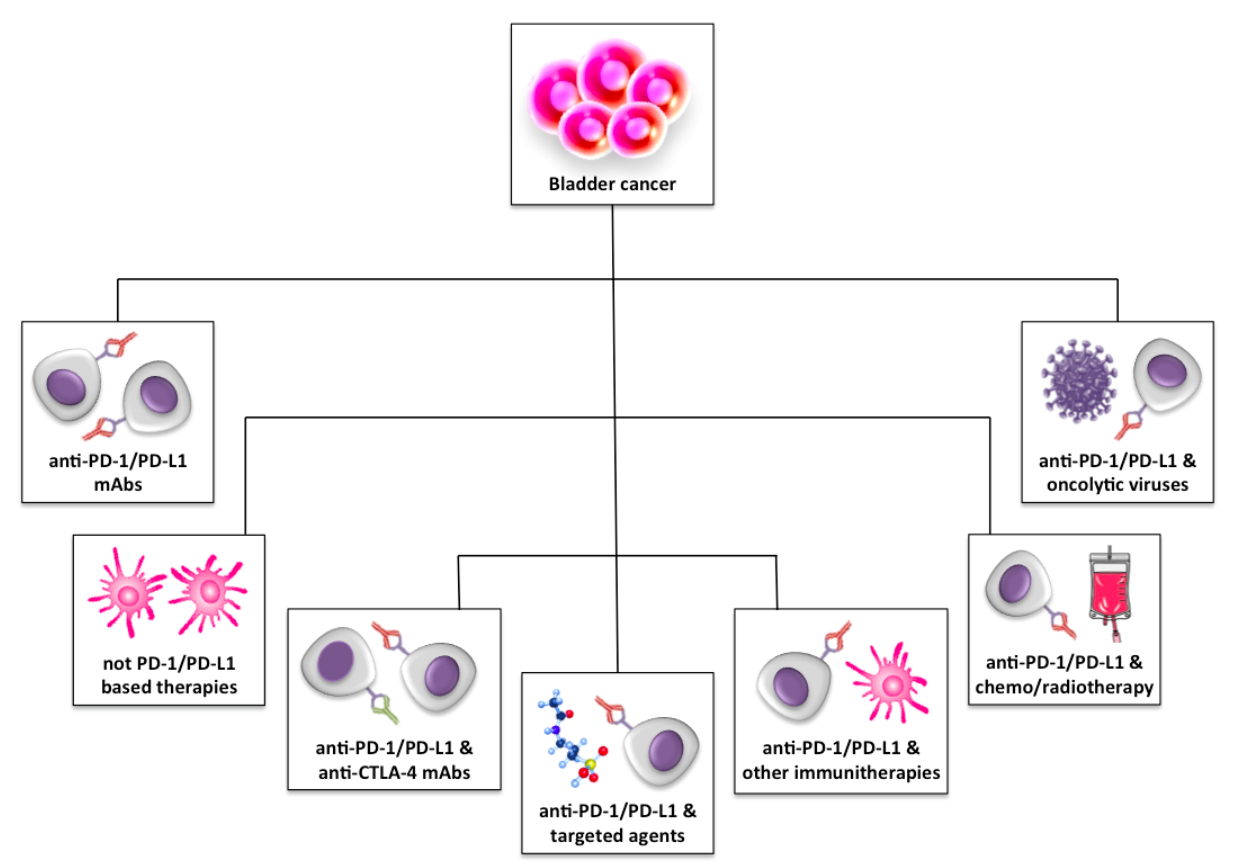




\begin{tabular}{|c|c|c|c|c|c|c|c|}
\hline TRIAL NAME & $\begin{array}{l}\text { IMMUNOTHERAPIC } \\
\text { AGENTS }\end{array}$ & TREATMENT ARMS & POPULATION & $\begin{array}{l}\text { PLANNED } \\
\text { PATIENTS } \\
\text { (N) }\end{array}$ & $\begin{array}{l}\text { PRIMARY } \\
\text { ENDPOINT }\end{array}$ & $\begin{array}{c}\text { DATE } \\
\text { STARTED }\end{array}$ & $\begin{array}{l}\text { PLANNED } \\
\text { COMPLATATION } \\
\text { DATE }\end{array}$ \\
\hline $\begin{array}{l}\text { NCT02853305 } \\
\text { Keynote-361 }\end{array}$ & Pembrolizumab & $\begin{array}{l}\text { A) Pembrolizumab } 200 \mathrm{mg} \\
\text { IV on Day } 1 \text { of each 3-week } \\
\text { cycle for a maximum of } 35 \\
\text { doses } \\
\text { B) Pembrolizumab + } \\
\text { Chemotherapy } \\
\text { (Cisplatin/Gemcitabine, or } \\
\text { Carboplatin/Gemcitabine) } \\
\text { C) Chemotherapy } \\
\text { (Cisplatin/Gemcitabine, or } \\
\text { Carboplatin/Gemcitabine) }\end{array}$ & $\begin{array}{l}\text { First line therapy } \\
\text { Patients with previously untreated } \\
\text { unresectable or metastatic urothelial } \\
\text { cancer }\end{array}$ & 990 & $\begin{array}{l}\text { PFS } \\
\text { OS }\end{array}$ & $\begin{array}{l}\text { September } \\
2016\end{array}$ & $\begin{array}{l}\text { March } \\
2020\end{array}$ \\
\hline NCT03036098 & $\begin{array}{l}\text { Nivolumab } \\
\text { Ipilimumab }\end{array}$ & $\begin{array}{l}\text { A) Nivolumab + Ipilimumab } \\
\text { combination } \\
\text { B) Standard of care } \\
\text { Chemotherapy } \\
\text { (Cisplatin/Gemcitabine, or } \\
\text { Carboplatin/Gemcitabine) }\end{array}$ & $\begin{array}{l}\text { First line therapy } \\
\text { Patients with previously untreated } \\
\text { unresectable or metastatic urothelial } \\
\text { cancer }\end{array}$ & 690 & $\begin{array}{l}\text { PFS } \\
\text { OS }\end{array}$ & $\begin{array}{l}\text { March } \\
2017\end{array}$ & $\begin{array}{l}\text { December } \\
2022\end{array}$ \\
\hline NCT02450331 & Atezolizumab & $\begin{array}{l}\text { A) Atezolizumab IV infusion } \\
1200 \mathrm{mg} \text { q } 3 \mathrm{w} \text { for } 16 \text { cycles } \\
\text { (up to } 1 \text { year) } \\
\text { B) Observation }\end{array}$ & $\begin{array}{c}\text { Adjuvant therapy } \\
\text { Patients with PD-L1 positive, high } \\
\text { risk muscle-invasive bladder cancer } \\
\text { after cystectomy }\end{array}$ & 700 & DFS & June 2017 & April 2022 \\
\hline $\begin{array}{l}\text { NCT02807636 } \\
\text { IMvigor130 }\end{array}$ & Atezolizumab & $\begin{array}{l}\text { A) Atezolizumab IV infusion } \\
1200 \mathrm{mg} \text { q } 3 \mathrm{w} \text { and } \\
\text { carboplatin AUC } 4,5 \mathrm{mg} / \mathrm{mL} \\
\text { min and gemcitabine IV } \\
\text { infusion } 1000 \mathrm{mg} / \mathrm{mq} \text { on } \\
\text { day } 1 \text { and } 8 \text { of each } 21 \text { day } \\
\text { cycle } \\
\text { B) placebo IV infusion q3w } \\
\text { with carboplatin and } \\
\text { gemcitabine }\end{array}$ & $\begin{array}{c}\text { First line therapy } \\
\text { Pz with loaclly advanced or } \\
\text { metastatic UCB who are ineligible to } \\
\text { receive cisplatin-based therapy/ }\end{array}$ & 1200 & $\begin{array}{l}\text { PFS } \\
\text { OS } \\
\text { AEs }\end{array}$ & June 2016 & July 2020 \\
\hline $\begin{array}{l}\text { NCT02603432 } \\
\text { JAVELIN } \\
\text { Bladder } 100\end{array}$ & Avelumab & $\begin{array}{l}\text { A) Avelumab q2w in } 4 \text { week } \\
\text { cycles plus BSC } \\
\text { B) BSC }\end{array}$ & $\begin{array}{l}\text { Maintaince treatment after first-line } \\
\text { chemotherapy }\end{array}$ & 668 & OS & April 2016 & July 2020 \\
\hline
\end{tabular}




\begin{tabular}{|c|c|c|c|c|c|c|c|}
\hline NCT03084471 & $\begin{array}{l}\text { Durvalumab } \\
\text { Tremelimumab }\end{array}$ & $\begin{array}{l}\text { Durvalumab monotherapy } \\
\text { or Durvalumab }+ \\
\text { Tremelimumab combination }\end{array}$ & $\begin{array}{l}\text { Metastatic or locally advanced } \\
\text { urothelial carcinoma progressed to } \\
\text { First line therapy/Advanced } \\
\text { maligancies }\end{array}$ & 1200 & $\begin{array}{l}\text { Safety: } \\
\text { number and } \\
\text { percentage } \\
\text { of } \\
\text { participants } \\
\text { with AESI }\end{array}$ & April 2017 & April 2022 \\
\hline $\begin{array}{l}\text { NCT02516241 } \\
\text { DANUBE }\end{array}$ & $\begin{array}{l}\text { Durvalumab } \\
\text { tremelimumab }\end{array}$ & $\begin{array}{l}\text { A) Durvalumab + } \\
\text { tremelimumab } \\
\text { B) Durvalumab } \\
\text { C) Standard of care } \\
\text { (Chemotherapy } \\
\text { Cisplatin, Carboplatin and } \\
\text { Gemcitabine) }\end{array}$ & $\begin{array}{c}\text { Metastatic or locally advanced } \\
\text { urothelial carcinoma }\end{array}$ & 1005 & $\begin{array}{l}\text { PFS } \\
\text { OS }\end{array}$ & November 2015 & July 2019 \\
\hline
\end{tabular}

Table 1. Ongoing phase III clinical trials with an immunotherapy agent in urothelial cancer.

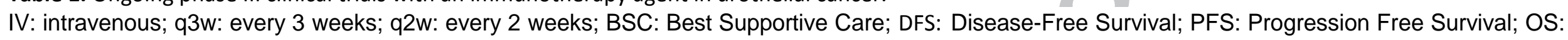

Overall Survival; AEs: Percentage of Participants with Adverse Events; AESI: adverse events of special interest. 


\begin{tabular}{|c|c|c|c|c|c|c|}
\hline Study & Drug & $\mathbf{N}$ & Setting & Comparator arm & Phase & $\begin{array}{l}\text { Primary } \\
\text { outcome }\end{array}$ \\
\hline \multicolumn{7}{|c|}{ PD-1 inhibitors } \\
\hline NCT02500121 & Pembrolizumab & 200 & maitenance after I line & Placebo & II & $\begin{array}{l}6 \text { months - } \\
\text { PFS }\end{array}$ \\
\hline NCT02736266 & Pembrolizumab & 90 & Neoadjuvant & NO & 11 & CRR \\
\hline NCT02625961 & Pembrolizumab & 260 & BCG failure, pT1-Ta, CIS & NO & II & DFS/CRR \\
\hline NCT02662062 & $\begin{array}{l}\text { Pembrolizumab + Cisplatin } \\
\text { and RT }\end{array}$ & 30 & $\begin{array}{l}\mathrm{T} 2-\mathrm{T} 4 \mathrm{a}, \mathrm{Nx} \text { or N0 } \\
\text { urothelial carcinoma }\end{array}$ & NO & 11 & Safety \\
\hline NCT02621151 & $\begin{array}{l}\text { Pembrolizumab } \\
+ \text { +Gemcitabine /RT }\end{array}$ & 54 & T2-T4a, N0, M0 & NO & II & 2year DFS \\
\hline NCT01174121 & Pembrolizumab + TIL & 290 & Advanced malignancies & NO & II & ORR \\
\hline NCT02690558 & $\begin{array}{l}\text { Pembrolizumab + Cisplatin - } \\
\text { Gemcitabine }\end{array}$ & 39 & Neoadjuvant & NO & II & ORR \\
\hline NCT02581982 & $\begin{array}{l}\text { Pembrolizumab } \\
+ \text { Paclitaxel }\end{array}$ & 27 & $\begin{array}{l}\text { previously treated } \\
\text { patients with } \\
\text { metastatic or locally } \\
\text { advanced UC }\end{array}$ & NO & II & ORR \\
\hline NCT02351739 & $\begin{array}{l}\text { Pembrolizumab + } \\
\text { ACP-196 }\end{array}$ & 75 & $\begin{array}{l}\text { previously treated } \\
\text { patients with } \\
\text { metastatic or locally } \\
\text { advanced UC }\end{array}$ & Pembrolizumab & II & ORR \\
\hline NCT02717156 & $\begin{array}{l}\text { Pembrolizumab }+ \\
\text { EphB4-HSA fusion protein }\end{array}$ & 60 & $\begin{array}{l}\text { previously treated } \\
\text { patients with } \\
\text { metastatic or locally } \\
\text { advanced UC }\end{array}$ & NO & II & Safety \\
\hline NCT02845323 & Nivolumab + Urelumab & 44 & $\begin{array}{l}\text { Neoadjuvant unfit to } \\
\text { cisplatin }\end{array}$ & Nivolumab & II & ORR \\
\hline NCT01928394 & Nivolumab + ipilimumab & 1150 & Advanced malignancies & $\begin{array}{l}\text { Nivolumab/Nivolumab } \\
+ \text { ipilimumab/ }\end{array}$ & II & ORR \\
\hline NCT02365766 & $\begin{array}{l}\text { Pembrolizumab + } \\
\text { Gemcitabine }\end{array}$ & 81 & $\begin{array}{l}\text { Neoadjuvant unfit to } \\
\text { cisplatin }\end{array}$ & NO & $1 / I I$ & Safety/ORR \\
\hline NCT02437370 & $\begin{array}{l}\text { Pembrolizumab + } \\
\text { Gemcitabine/docetaxel }\end{array}$ & 38 & $\begin{array}{l}\text { previously treated } \\
\text { patients with } \\
\text { metastatic or locally } \\
\text { advanced UC }\end{array}$ & NO & $1 / I I$ & Safety \\
\hline NCT02619253 & Pembrolizumab + Vorinostat & 42 & $\begin{array}{l}\text { previously treated } \\
\text { patients with } \\
\text { metastatic or locally } \\
\text { advanced UC }\end{array}$ & NO & $1 / I 1$ & Safety \\
\hline NCT02501096 & Pembrolizumab + Levatinib & 250 & Advanced malignancies & NO & $1 / I I$ & Safety \\
\hline NCT02393248 & $\begin{array}{l}\text { Pembrolizumab + } \\
\text { INCB054828 }\end{array}$ & 150 & Advanced malignancies & CT + INCB054828 & $1 / I I$ & Safety \\
\hline
\end{tabular}




\begin{tabular}{|c|c|c|c|c|c|c|}
\hline NCT02925533 & Pembrolizumab + B 701 & 12 & $\begin{array}{l}\text { previously treated } \\
\text { patients with } \\
\text { metastatic or locally } \\
\text { advanced UC }\end{array}$ & NO & 1 & Safety \\
\hline NCT02443324 & $\begin{array}{l}\text { Pembrolizumab + } \\
\text { Ramucirumab }\end{array}$ & 155 & Advanced malignancies & NO & 1 & Safety \\
\hline NCT03006887 & Pembrolizumab + Levatinib & 10 & Advanced malignancies & NO & 1 & Safety \\
\hline NCT02856425 & $\begin{array}{l}\text { Pembrolizumab + } \\
\text { Nintendanib }\end{array}$ & 18 & Advanced malignancies & NO & 1 & Safety \\
\hline NCT02043665 & Pembrolizumab + CVA21 & 90 & Advanced malignancies & NO & 1 & ORR \\
\hline NCT02346955 & $\begin{array}{l}\text { Pembrolizumab + CM-24 } \\
\text { (MK-6018) }\end{array}$ & 27 & Advanced malignancies & NO & 1 & Safety \\
\hline NCT02324582 & Pembrolizumab + BCG & 15 & $\begin{array}{l}\text { high risk superficial } \\
\text { bladder cancer }\end{array}$ & NO & 1 & Safety \\
\hline NCT02808143 & Pembrolizumab + BCG & 27 & $\begin{array}{l}\text { high risk superficial } \\
\text { bladder cancer } \\
\text { refractory to BCG }\end{array}$ & NO & 1 & Safety \\
\hline NCT02432963 & $\begin{array}{l}\text { Pembrolizumab + Vaccine } \\
\text { therapy }\end{array}$ & 19 & Advanced malignancies & NO & 1 & Safety \\
\hline NCT02475213 & $\begin{array}{l}\text { Pembrolizumab + } \\
\text { enoblituzumab }\end{array}$ & 75 & Advanced malignancies & NO & 1 & Safety \\
\hline NCT02560636 & $\begin{array}{l}\text { Pembrolizumab + } \\
\text { Radiotherapy }\end{array}$ & 34 & $\begin{array}{l}\text { Metastatic or locally } \\
\text { advanced UC }\end{array}$ & NO & I & Safety \\
\hline NCT02826564 & $\begin{array}{l}\text { Pembrolizumab + } \\
\text { Stereotactic Body } \\
\text { Radiotherapy }\end{array}$ & 20 & $\begin{array}{l}\text { previously treated } \\
\text { patients with } \\
\text { metastatic or locally } \\
\text { advanced UC }\end{array}$ & NO & 1 & Safety \\
\hline NCT02614456 & $\begin{array}{l}\text { Nivolumab + interferon } \\
\text { gamma }\end{array}$ & 15 & Advanced malignancies & NO & 1 & Safety \\
\hline NCT02897765 & Nivolumab + NEO-PV-01 & 90 & Advanced malignancies & NO & 1 & Safety \\
\hline NCT02496208 & Nivolumab + Cabozantinib & 113 & $\begin{array}{l}\text { previously treated } \\
\text { patients with } \\
\text { metastatic or locally } \\
\text { advanced UC }\end{array}$ & $\begin{array}{l}\text { Nivolumab + cabozantinib + } \\
\text { Ipilimumab }\end{array}$ & 1 & Safety \\
\hline NCT02903914 & Nivolumab + CB-1158 & 236 & Advanced malignancies & Nivolumab / CB 1158 & 1 & Safety \\
\hline NCT02636036 & Nivolumab + Enadenotucirev & 30 & Advanced malignancies & NO & I & Safety \\
\hline
\end{tabular}




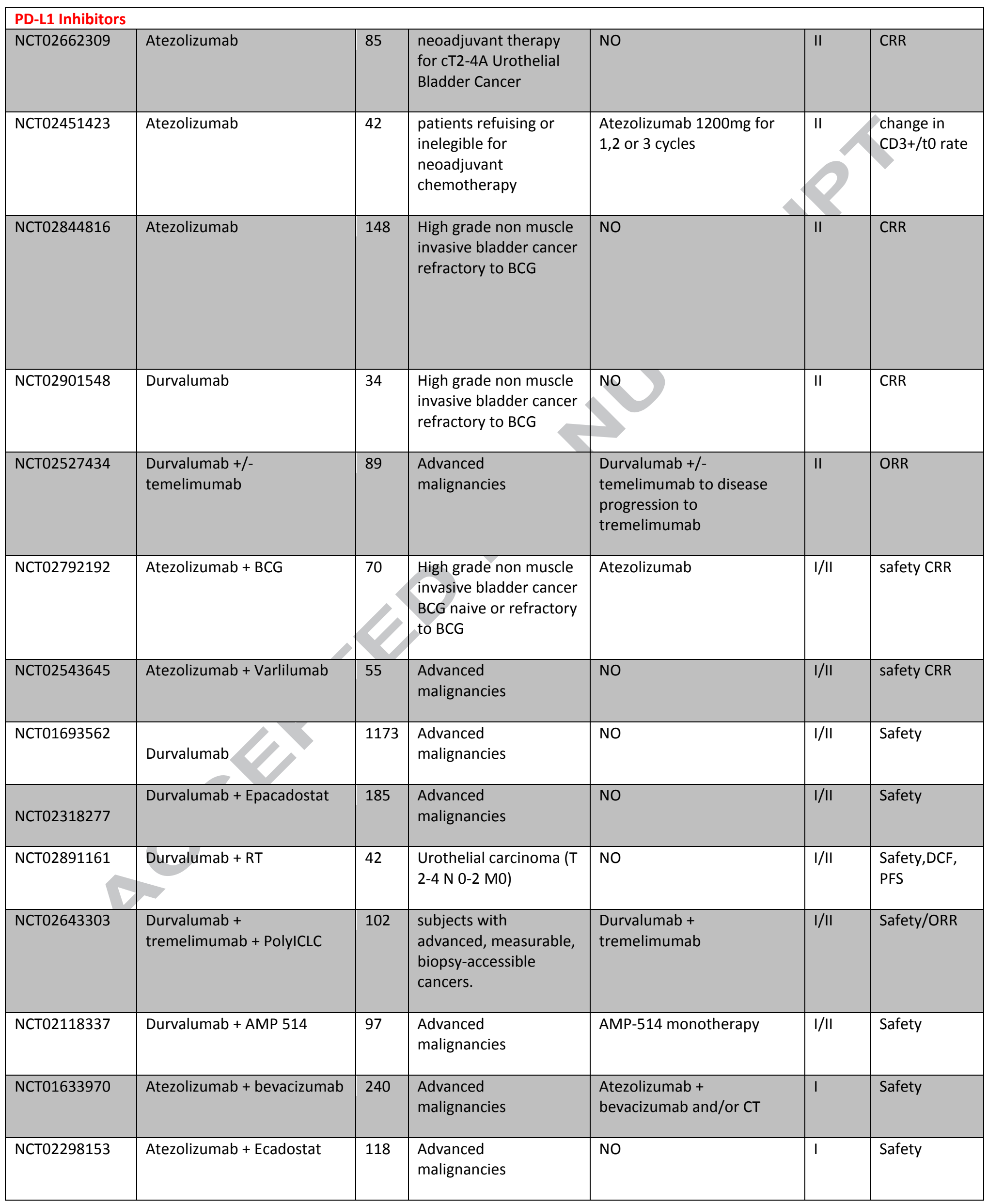




\begin{tabular}{|c|c|c|c|c|c|c|}
\hline NCT02655822 & Atezolizumab + CPI-444 & 534 & $\begin{array}{l}\text { Advanced } \\
\text { malignancies }\end{array}$ & NO & 1 & Safety \\
\hline NCT01772004 & Avelumab & 1706 & $\begin{array}{l}\text { Advanced } \\
\text { malignancies }\end{array}$ & NO & 1 & Safety \\
\hline NCT01943461 & Avelumab & 57 & $\begin{array}{l}\text { Advanced } \\
\text { malignancies }\end{array}$ & NO & 1 & Safety \\
\hline NCT02994953 & Avelumab + NSH-IL12 & 30 & $\begin{array}{l}\text { Advanced } \\
\text { malignancies }\end{array}$ & NO & 1 & Safety \\
\hline NCT02546661 & $\begin{array}{l}\text { Durvalumab + } \\
\text { olaparib/AZD4547/Vistuserti } \\
\text { nib }\end{array}$ & 110 & $\begin{array}{l}\text { Muscle invasive } \\
\text { bladder cancer } \\
\text { progressed on prior } \\
\text { treatment }\end{array}$ & $\begin{array}{l}\text { Durvalumab/olaparib/AZD4 } \\
\text { 547/vistusertinib } \\
\text { monotherapy }\end{array}$ & 1 & Safety \\
\hline NCT02812420 & $\begin{array}{l}\text { Durvalumab + } \\
\text { tremelimumab }\end{array}$ & 15 & $\begin{array}{l}\text { muscle invasive bladder } \\
\text { cancer inelegible for } \\
\text { cisplatin based } \\
\text { neoadjuvant therapy }\end{array}$ & NO & 1 & Safety \\
\hline \multicolumn{7}{|l|}{$\begin{array}{l}\text { CTLA-4 } \\
\text { Inhibitors and } \\
\text { other immuno } \\
\text { agents }\end{array}$} \\
\hline NCT03022825 & ALT-803 + BCG & 80 & $\begin{array}{l}\text { High grade non muscle } \\
\text { invasive bladder cancer } \\
\text { refractory to BCG }\end{array}$ & BCG & II/III & CRR \\
\hline NCT01524991 & $\begin{array}{l}\text { Ipilimumab + platinum based } \\
\text { chemotherapy }\end{array}$ & 36 & $\begin{array}{l}\text { Patients with untreated } \\
\text { metastatic or locally } \\
\text { advanced UC }\end{array}$ & NO & II & one year OS \\
\hline NCT02138734 & ALT-804 + BCG & 81 & $\begin{array}{l}\text { non muscle invasive } \\
\text { bladder cancer }\end{array}$ & BCG & $1 / I I$ & Safety \\
\hline NCT01625260 & ALT-801 + Gemcitabine & 52 & $\begin{array}{l}\text { High grade non muscle } \\
\text { invasive bladder cancer } \\
\text { refractory to BCG }\end{array}$ & NO & $1 / I I$ & Safety \\
\hline NCT01326871 & $\begin{array}{l}\text { ALT- } 801+\text { Cisplatin and } \\
\text { Gemcitabine }\end{array}$ & 90 & $\begin{array}{l}\text { Metastatic or muscle } \\
\text { invasive bladder cancer }\end{array}$ & ALT-801 - Gemcitabine & $1 / 11$ & Safety \\
\hline NCT02381314 & Ipilimumab + Enoblituzumab & 84 & Advanced Malignancies & NO & $\mathrm{I}$ & Safety \\
\hline NCT02628535 & MGD-009 & 114 & Advanced Malignancies & NO & 1 & Safety \\
\hline
\end{tabular}

Table 2.

Ongoing phase II/III,II, I/II and I studies with immune-checkpoints inhibitors, CTLA-4 Inhibitors and other immuno agents.

OS: Overall Survival, PFS: Progression Free survival, CRR: Complite response rate, DFS: Disease Free Survival 


\section{Highlights}

1. Atezolizumab and Pembrolizumab showed in phase II (Atezolizumab and Pembrolizumab) and phase III (Pembrolizumab) trials to improve clinical outcome of patients progressed to platinum based therapy.

2. Atezolizumab failed to show OS benefit over chemotherapy in a phase III trial for patients progressed to platinum based therapy.

3. Immunotherapy improve clinical outcome of patients unfit to standard first line platinum therapy

4. We describe the active or ongoing clinical trials involving Programmed Death Ligand 1 (PD-L1), Programmed Death receptor 1 (PD-1) and Cytotoxic-T Lymphocyte Antigen 4 (CTLA 4) inhibitors in urothelial carcinoma focusing our attention on the developing new immune-agents and combination strategies with immune-checkpoint inhibitors. 


\section{Conflict of interest statement}

All authors declare that they have no conflicts of interest

Conflicts of interest: none for all authors.

Financial disclosures: none for all authors. 